\title{
Monitoring of Soil Surface under Wind and Water Erosion by Photogrammetry
}

\author{
Shigeoki Moritani et al. ${ }^{*}$ \\ Arid Land Research Center, Tottori University, \\ Japan
}

\section{Introduction}

Soil degradation resulting from accelerated water and wind-induced erosion is a serious problem in drylands, and will remain so throughout this century. The detachment and transport of soil particles degrade the fertility of agricultural land and consequently reduce its productivity (Lyles and Tartako 1986 ).Many of the particles involved in soil erosion processes, such as raindrops, wind velocity, soil aggregates, sediment, and siltation have characteristic dimensions on the millimeter scale (Huang 1998). The addition of organic matter increases the connection between aggregate by physical and chemical bounding. The strongly bonding aggregation induces the increase of soil porosity and permeability, which result the decrease of water erosion. The bigger aggregate also decrease the wind erosion due to their heaviness.

The modeling and quantification of such processes require detailed measurements of the physical, chemical, and biological properties of soils (Soil Conservation Service 1976). However, these measurements are too slow, tedious, and expensive for routine or regular monitoring.

Several researchers have already used aerial photography to assess soil erosion. A precise form of this photography, photogrammetry, has the advantage of very efficiently and cost effectively providing detailed information about a large area. Together with aerial photography, the use of remotely sensed data forms the basis for land use mapping and change detection (Pellikka et al. 2004). In particular, for inaccessible areas, photogrammetry is far superior to traditional ground surveys. The subsequent convergence in recent years of photogrammetry and digital imaging technology has led to an increase in the use of digital elevation models (DEMs) in modern studies involving the monitoring of landscape changes (Prosser and Aberneathy 1996; DeRose et al. 1998).

The areas measured experimentally in microtopographical studies of soil erosion range from 1 to approximately $20 \mathrm{~m}^{2}$. In general, the DEMs used for analysis have grid resolutions of 1 to $15 \mathrm{~mm}$ (Elliot et al. 1997; Darboux and Huang 2003). A variety of instruments and methods are used by soil scientists to acquire measurement coordinates, including mechanical point gauges (Elliot et al. 1997) that make contact with the soil surface,

"Tahei Yamamoto, Henintsoa Andry, Mitsuhiro Inoue, Taku Nishimura, Haruyuki Fujimaki, Reiji Kimura and Hirotaka Saito

Arid Land Research Center, Tottori University, Japan 
optoelectronic measurement devices such as laser scanners (Huang et al. 1988; Darboux and Huang 2003), and image processing techniques (Abd-Elbasit et al. 2008). Point gauges have been widely replaced by laser scanners, because the former make contact with the soil and can thus disturb it or sink into it (Römkens et al. 1988). While laser scanners have proven their usefulness in many experiments, a photogrammetric system is more advanced, comparatively cheaper, and provides images and morphological properties simultaneously (Hodge et al. 2009; Chandler et al. 2005).

Automated digital photogrammetry allows DEMs to be generated with sufficient resolution for microtopographical analysis. Jeschke (1990) applied correlation matching to soft-copy images taken by a Zeiss SMK 40 camera to analyze soil microtopography. Recent advances in digital image processing and camera calibration techniques make it possible to use the digitized images taken by consumer-grade analog cameras to automate the generation of DEMs (Brasington and Smart 2003; Abd-Elbasit et al. 2009) Some researchers, e.g., Chandler et al. (2002) and Lascelles et al. (2002), have calibrated consumer-grade cameras and employed the images taken with them to generate DEMs automatically on digital photogrammetric workstations, which are becoming increasingly accessible to nonphotogrammetrists.

Analytical photogrammetry has often been used in geomorphological studies of gully and rill formation (Elliot et al. 1997; Pyle and Richards 1997; Helming et al. 1998; DeRose et al. 1998; Pellikka et al. 2004; Rieke-Zapp and Nearing 2005). In these previous studies, the DEM resolutions were generally produced from photographs taken under a no-rainfall condition, i.e., the photographs were taken just before and after the rainfall and wind events (RiekeZapp and Nearing 2005). Moreover, study reporting this method to monitor sheet and wind erosions, which predominate in drylands, is relatively few. It is necessary to evaluate the reliability of the DEM produced using either a camera and rainfall simulator or camera and wind tunnel at the laboratory scale before field scale application. The purpose of this study was to generate DEMs with high spatial and temporal resolutions from soil surfaces that developed sheet and wind erosions. Digital photogrammetry was used to measure the erosion rates and to monitor the evolution of the soil surface network under laboratory simulated conditions.

\section{Overview of the photogrammetry system}

In order to study in three dimensions the soil surface evolution that results from water erosion, a new automated photogrammetry system was developed by Tottori University's Arid Land Research Center (ALRC), in collaboration with Asia Air Survey Co., Ltd. Fig. 1 shows a flow chart of this photogrammetry system (Moritani et al. 2006).

Two Nikon D2H digital cameras were focused on the center of the target object, as shown in Fig. 2. A focus length of $50 \mathrm{~mm}$ was used. The CCD sensor had a matrix of $2464 \times 1632$ picture elements (pixels). The distance between two pixel centers, $\delta_{C C D}$, was $0.0094 \mathrm{~mm}$. The memory card used was capable of storing approximately 60 7.9-MB images, allowing the analysis to be performed on uncompressed Tagged Image File Format (TIFF) images. A PC software program was used to analyze the pictures taken by the $\mathrm{D} 2 \mathrm{H}$ cameras. The inner orientation factor was obtained from a calibration factor called the calibration field (CF), as shown in Fig. 3.

It is well known that even two cameras of the same type do not have exactly equal characteristics such as the shape of the lens and the spatial arrangement of the CCD and lens (Weng et al. 1992). This made inner orientation calibration necessary for each camera to 
obtain more accurate DEM data. As shown in Fig. 5, the camera calibration was performed using a three-dimensional calibration field (CF) with 32 well-distributed control points, known with an accuracy of $0.2 \mathrm{~mm}$. This CF was equipped with 20 square poles with three different lengths, and 12 points on the planar table (which was placed between the square poles by 3 horizontal lines). Pictures of the CF were taken by each camera from a fixed distance, $H$ (camera pair to object), of approximately $3.0 \mathrm{~m}$. During this photography process, the camera position was shifted parallel with the $\mathrm{CF}$ board to capture six multiple images of the entire area of the image plane, including every corner of the image plane, where there were large amounts of radial distortion. The least-square of the bundle adjustment among these images was then used to determine the inner orientation parameters, lens focus length, principal point offsets, and radial distortion (Hung and Mitchell 1995; Rieke-Zapp et al. 2001; Abd-Elbasit et al. 2008).

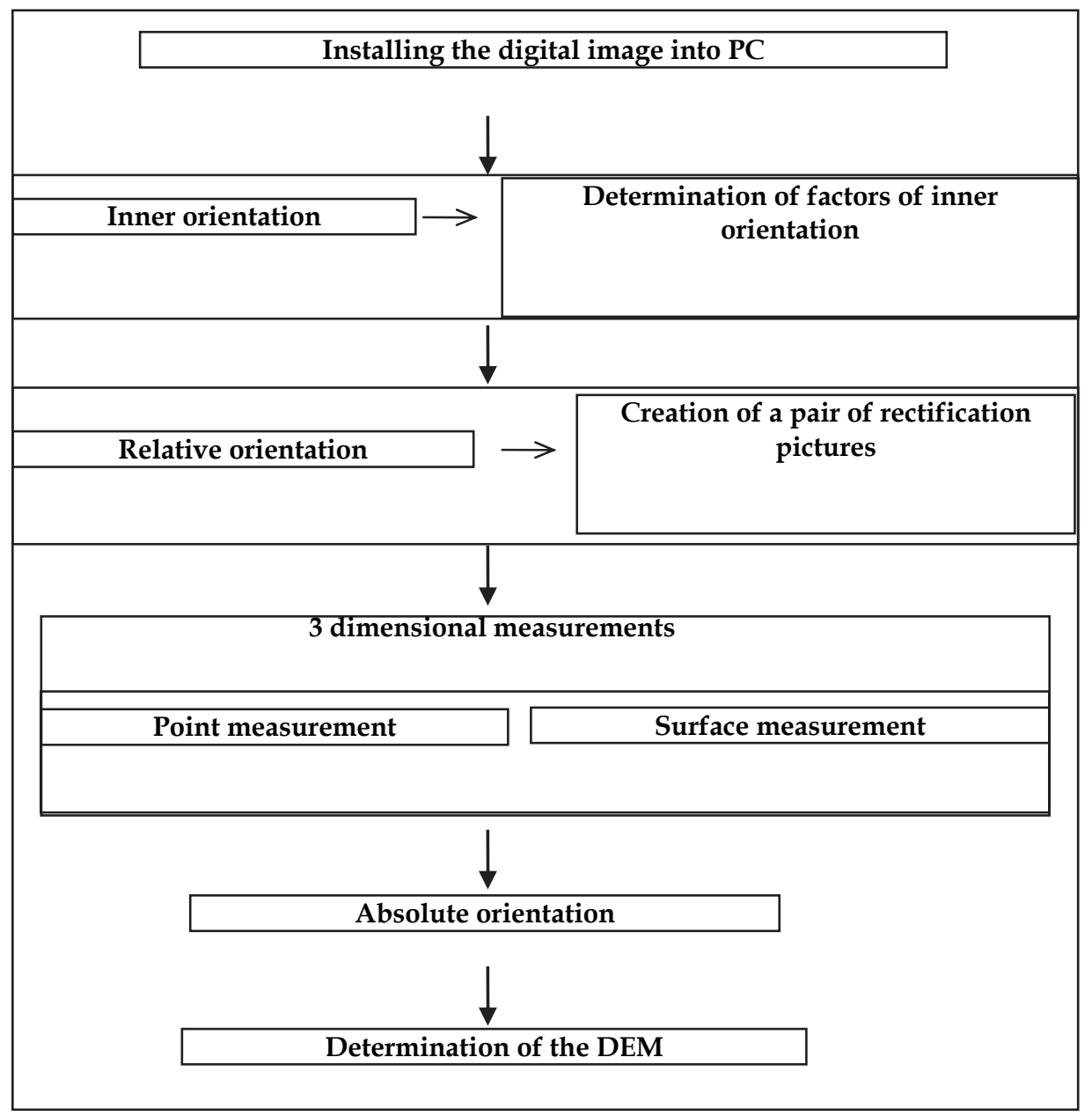

Fig. 1. Flowchart of photogrammetry measurement. 


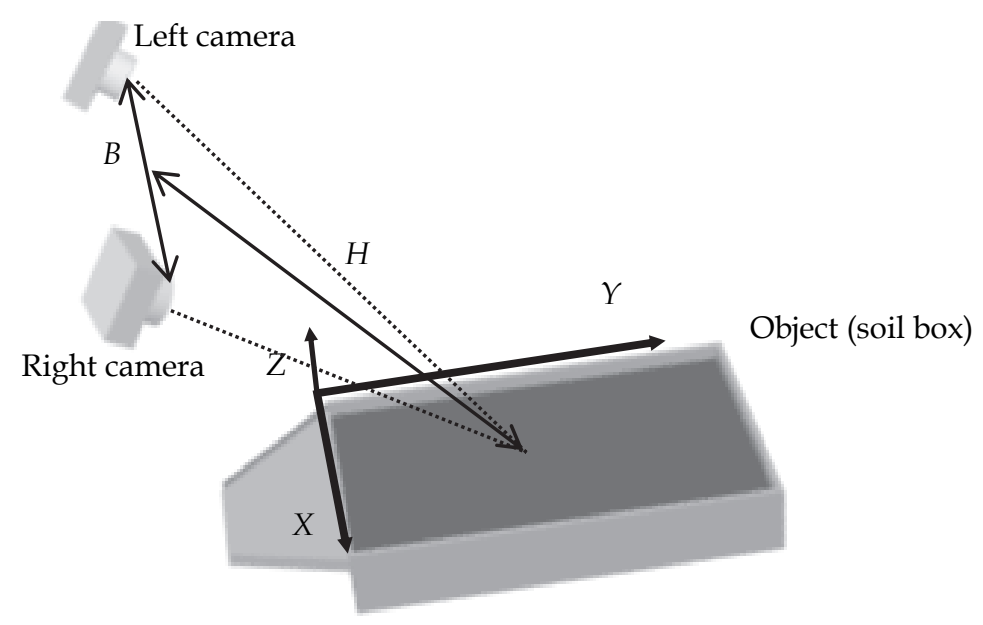

Fig. 2. The layout of two cameras and object. Each dashed line is oriented direction by pair of cameras

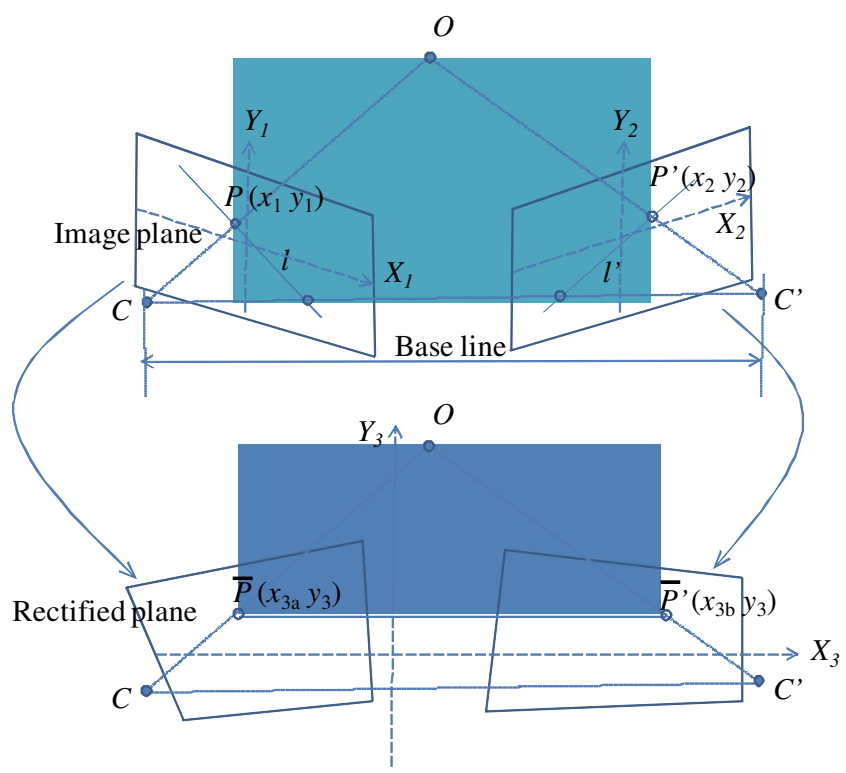

Fig. 3. Illustration of the coplanar condition and rectification. The object point $O$ is projected onto the image planes corresponding to $P$ and $P^{\prime}$ from different viewpoints of $C$ and $C^{\prime}$. The coplanar is defined by the point $O$ and the base line. $l$ and $l$ 'are the epipolar lines, which are the intersections of the coplanar and the two image planes (upper). The rectification involves both image planes to be at the same coordinate system $\left(X_{3} Y_{3}\right)$ and makes the $y$-axis of $P$ and $P^{\prime}$ to be at the same position $\left(\bar{P}\right.$ and $\left.\overline{P^{\prime}}\right)$. 
The gradient of the pair of pictures was adjusted to minimize the parallax, and then the relative orientation was determined with the resulting points fixed on the $x$-axis. The result of this process is called a rectified photograph. The relative orientation yielding the rectified images was determined by a complicated equation based on a geometric consideration of the coplanar condition (Fig. 3), in which the image points $P$ and $P^{\prime}$ always lay on the epipolar lines 1 and l', respectively (Huang and Mitchell 1995; Heipke 1997). The rectification required that both image planes used the same coordinate system $\left(X_{3}, Y_{3}\right)$ and that the $y$ axes of $P$ and $P^{\prime}$ were at the same position $\left(\bar{P}\right.$ and $\left.\overline{P^{\prime}}\right)$. This reduced the search space for $P$ and $P^{\prime}$ from two dimensions to one, and thus increased the speed and reliability of the matching (Jeong et al. 2004).

The three-dimensional calculation consisted of two methods: (1) point measurement and (2) surface measurement. Point measurement was used for visual matching to acquire a limited number of DEMs, while surface measurement was used to automatically calculate an enormous number of dense DEMs such as for the contour line of a surface. In the point measurement, as illustrated in Fig. 4, the cursor (shown as a $i$ ) was first moved onto a reference pixel point selected in the left rectified picture. The corresponding cursor in the right picture automatically followed along the y-axis to a position that matched that on the left. Then, the cursor in the right picture was moved along the x-axis (epipolar line) to the same corresponding point. Three-dimensional data were calculated based on the absolute orientation from the $x_{1} y_{1}$ and $x_{2} y_{2}$ coordinates of the image points (Fig. 3). In the case of surface measurement, a quadrangular analytical frame was placed in each of the rectified images. These frames were aligned as closely as possible to cover and represent the same image area to reduce the matching error. Finally, approximately 16,000 pixels (shown as 0 marks) were calculated and automatically matched in a few seconds to acquire DEMs, based on a coarse-to-fine matching strategy using multi-resolution representations, with a Laplacian of Gaussian filter (Kim et al. 1997; Cruz et al. 1995).

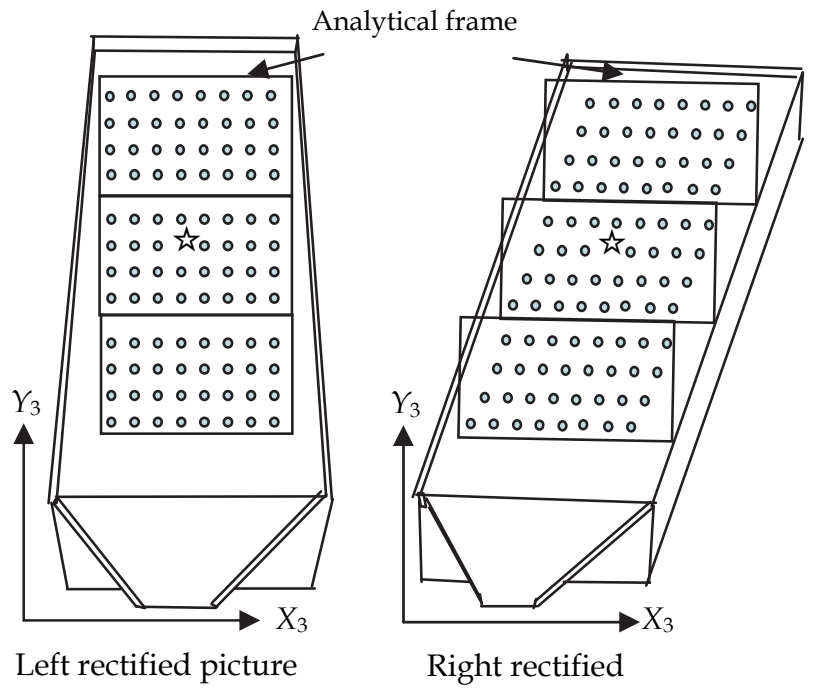

Fig. 4. Three-dimensional measurement in rectified photograph. The marks of is and $\circ$ in the figure indicate the measurement point used for point and surface measurement, respectively. 


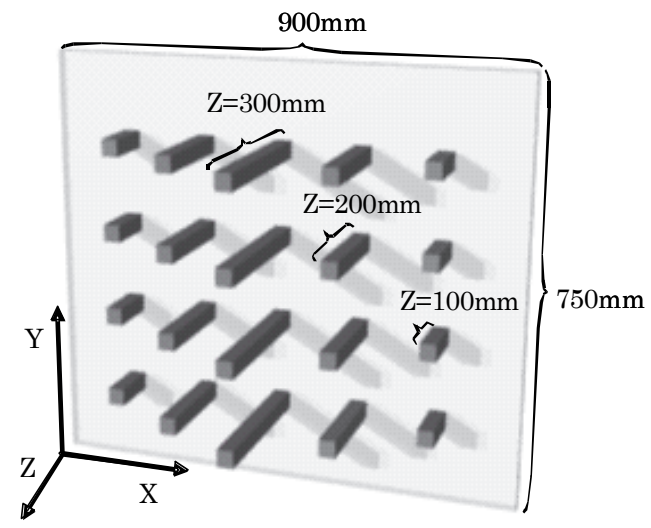

Fig. 5. Calibration field (CF)

\section{Materials and methods}

\subsection{Accuracy of the DEM}

The accuracy of this inner orientation was examined using the known DEM values of the CF board. The positions of the two D2H cameras were oriented to the CF board to include the 32 ground control points (GCPs). The CF was photographed at five different positions, ranging from a distance $H$ of 2.0 to $6.0 \mathrm{~m}$, and with a base length $B$ (between the cameras) of $1.0 \mathrm{~m}$. The point measurement process was used for the three-dimensional measurements of the 32 points on the $\mathrm{CF}$, and the precision of the system was determined by comparing the results after the inner orientation against those without calibration.

The accuracy of the photogrammetry system was also evaluated under a no-rainfall condition using a soil box with a width, length, and height of $30 \mathrm{~cm}, 50 \mathrm{~cm}$, and $10 \mathrm{~cm}$, respectively. Sandy soil was packed into the soil box and twenty nails were inserted into the soil surface to be used as "unknown" measurement points, with a $\times$ mark made on the top of each nail. The measured values, $M_{p}(\mathrm{~mm})$, on the z-axis were obtained using the point gauge method similar to that described by Abd-Elbasit et al. 2009, which consist of vertical pins, with wooden supporter, stinging on the nails put on the soil surface. A micrometer caliper was used to record the elevation of the soil surface by measuring the length of each pin with accuracy in the order of $\pm 0.01 \mathrm{~mm}$ (Model 19971, Shinwa Rules Co., LTD).

Point measurement was used to determine the photogrammetric value $A_{p}(\mathrm{~mm})$ on the zaxis, with ten marks on the frame of the soil box used as the ground control points (GCPs). The object was then photographed from 11 different positions, with $H$ values ranging from 2.4 to $4.7 \mathrm{~m}$ and $B$ values ranging from 0.3 to $1.0 \mathrm{~m}$. Then, the simulated depth of the soil erosion was evaluated after removing $50 \mathrm{mg}(36 \mathrm{~mL})$ of the air-dried sandy soil from the soil surface. This process was repeated 16 times until approximately $800 \mathrm{~mL}$ of soil was collected. The surface measurement process was used to calculate the DEM of the soil surface in each image. The average depth of the eroded soil, $A_{s}(\mathrm{~mm})$, was calculated from the average value of the DEMs on the z-axis, while the value of Ms (mm) was calculated based on the amount of collected soil $(\mathrm{g})$, the bulk density $\left(\mathrm{g} / \mathrm{cm}^{3}\right)$, and the measured area (cm2). 


\subsection{Accuracy of the DEM under the rainfall application}

Water erosion experiment was conducted using the rainfall simulator at ALRC. Three soil bulk densities, $0.91,0.98$, and $1.09 \mathrm{~g} / \mathrm{cm}^{3}$ were prepared, which was taken from a paddy field in Tottori prefecture, Japan. The soil was saturated from the bottom of the soil box with tap water, and then gravimetrically drained for one day to obtain a condition similar to the soil's field capacity. Simulated rain was delivered from a tower $12 \mathrm{~m}$ high. The rainfall distribution uniformity, which was calculated from the equation of uniformity coefficient developed by Christiansen, was set at $80 \%$, and about $85 \%$ of the drops had a diameter of less than $2 \mathrm{~mm}$ (Andry et al. 2007). A rainfall intensity of $60 \mathrm{~mm} / \mathrm{h}$, developing an energy of $27.1 \mathrm{~J} \mathrm{~m}^{-2} \mathrm{~mm}^{-1}$ (Van Dijk et al. 2002; Andry et al. 2008), was applied for an hour to the soil box under a $10^{\circ}$ slope. The runoff and splashed soil samples were collected every 5 or 10 minutes, just after taking pictures at $H=2.7$ and $B=0.8$. The two $\mathrm{D} 2 \mathrm{H}$ cameras were controlled with a cable release in order to simultaneously capture a pair of images and suppress the camera shake from clicking the shutter. This helped to shorten the time for the photogrammetry since the GCP points in each image were represented by the same pixels. A high optimal image quality was attained by using an aperture setting of $f / 5.6$ and a 1/250 s exposure time, which was sufficiently rapid to follow the flow of the runoff water on the soil surface. The splashed soil was collected on a sheet that was placed under the soil box. This sheet also helped to reduce the effect of halation in the images as a result of direct sunlight on the soil surface. The surface measurement process was used to obtain the value of $A_{s}(\mathrm{~mm})$. The measurement area for the DEM was reduced to $80 \%$ of the entire soil surface, because the shade produced by the sides of the soil box, as seen in the images, was removed from the study. The value of the eroded soil depth, $M_{s}(\mathrm{~mm})$, was calculated from the amount of the soil loss obtained after oven dried at $105^{\circ} \mathrm{C}$ for 48 hours, each initial soil bulk density and soil surface area.

\subsection{Generating DEM of soil surface induced by wind erosion}

The sandy soil is high tolerance against water erosion because of its high permeability. However sandy soil is easily transported by wind erosion, which lead to damage for agriculture. In the field, sand particles start to move as saltation when wind velocity is reaching the critical friction velocity. The particle of saltation crashes another particle in upward, which result in the acceleration of wind erosion. Wind tunnel is usually designed with the long length of working section such as 7 to $16 \mathrm{~m}$ enough to studying saltation and crash (Shao et al, 1993; Liu et al, 2007). However, this wind tunnel size costs much and also occupies large space. In this research the wind tunnel experiment was conducted inside an existence climate chamber whose width, height and length are 2, 2, and $3 \mathrm{~m}$, respectively. This chamber can be used to control wind velocity at maximum of $3 \mathrm{~m} / \mathrm{s}$ which is not enough for producing wind erosion. As a result, the wind tunnel was redesigning in order to produce a wind velocity of $12 \mathrm{~m} / \mathrm{s}$ by narrowing the cross-section of wind path by wood boards.

The friction speed is usually determined from the altitudinal profile of wind velocity. The wind speed closed to zero at the soil surface due to increase in soil roughness which in turn increases the resistance against wind. The logarithm of height increases the wind velocity proportionally. The friction speed is defined as this gradient of proportional line (Leys and Raupach, 1991). The wind tunnel used was low height of $20 \mathrm{~cm}$ which was not enough to measure the profile of wind by altitude. Therefore the wind velocity at $20 \mathrm{~cm}$ height was representative as measured velocity. The wind velocity when sand particle started taking off was considered as critical wind velocity. 
The dune sand was put inside the soil box whose width, length and height were 23,35 , and 3 $\mathrm{cm}$, respectively. The soil box with sand was fit in the opening on basal plane. In front of the soil box, the inclined plane was put to prevent the eddy flow at edge of soil box. Additionally, the effect of organic matter incorporated in the dune sand was assessed on the wind erosion. The organic matter made from bark of acicular tree which consists of bark of cedar and cypress at the weight ratio of 80 to $20 \%$. The mixing weight ratios used in this study were $0 \%$ as control, and 1.0, 5.0, 10 and 100\%. Wind was applied after packing the soil in soil box. At first, wind velocity of $4 \mathrm{~m} / \mathrm{s}$ was applied for $3 \mathrm{~min}$ on the soil box known weight. Then the soil box was weighted after wind, and the soil was again refilled with soil. And next, the wind velocity was incremented by $1 \mathrm{~m} / \mathrm{s}$ and repeated same procedure until the velocity reaching $12 \mathrm{~m} / \mathrm{s}$. The eroded soil (cm/hour) was calculated from the following Eqn 1.

$$
Q=\frac{W}{\delta \times A \times T}
$$

, where $W$ is the difference of weight of soil box $(\mathrm{g})$ between before and after wind. $\delta, A$ and $T$ are the bulk density $\left(\mathrm{g} / \mathrm{cm}^{3}\right)$, surface area of soil box $\left(\mathrm{cm}^{2}\right)$ and time (hour) under wind.

The photogrammetry experiment to capture the wind ripple was carried out in the straightline puff wind tunnel at ALRC (Fig.6). There were difficulties encountering when taking photograph during the wind application. The cameras were not easily to put inside the wind tunnel due to the small space. Even if cameras were put, the picture was not clear due to the camera shaking by wind energy and the interfering of the saltation as well. As a result, the experiments of photogrammetry and soil sampling were separately conducted, which was not the same with rainfall experiment that could be performed simultaneously. Moreover, to overcome these difficulties, the experiment of photogrammetry was performed only on the working section of this wind tunnel with open superior wall of $2.0 \mathrm{~m}$ long, $0.45 \mathrm{~m}$ wide, and $0.55 \mathrm{~m}$ high. A $2 \mathrm{~cm}$ depth of air-dried sandy soil was placed in the wind tunnel and subjected to wind velocity of $4.5 \mathrm{~m} / \mathrm{s}$ for $45 \mathrm{~min}$. The soil surface was photographed using a selected target object at a distance of $0.6 \mathrm{~m}$, using a base length of $0.3 \mathrm{~m}$, before and after the wind events. The DEM soil surface data were obtained using the surface measurement process. The accuracy of the photogrammetry system was evaluated using the DEM values for 20 nails on the z-axis, i.e., comprising the $\mathrm{Mp}(\mathrm{mm})$ values measured from the soil surface with a point gauge against the Ap values from the point measuring method.

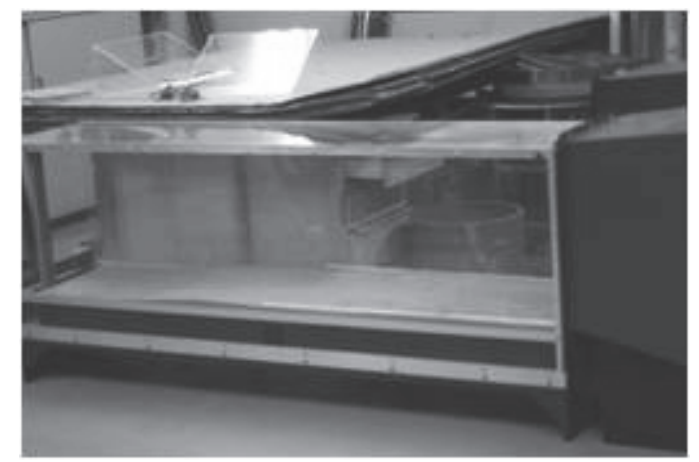

Fig. 6. Layout of wind tunnel 


\section{Results and discussions}

\subsection{The influence of inner orientation on the DEM accuracy}

The accuracy of the DEM along the z-axis, which is the soil depth $\delta_{Z}$, was affected by (1) the resolution of the camera, $\delta_{C C D}(\mathrm{~mm}),(2)$ the distance between the camera and object, $H(\mathrm{~m})$, (3) the base distance between the pair of cameras, $B,(\mathrm{~m})$, and $(4)$ the focus length $f_{\mathrm{C}}(\mathrm{mm})$

(Fig. 2). The relationships between these 4 factors can be expressed as shown in Eqn 2 (Moritani et al, 2006):

$$
\delta_{Z}=\frac{H}{f} \frac{H}{B} \delta_{C C D}
$$

It was found that accuracy was also influenced by (5) the declinations in the principal coordinate points of the lenses in the longitudinal and horizontal directions and (6) the distortion of the lenses. However, factors (5) and (6) can be compensated for by calculating the inner orientation of each camera.

The precision along the z-axis was evaluated using the mean absolute error (MAE) and the mean relative error $(M R E)(\%)$, shown respectively in Eqns 3 and 4:

$$
\begin{gathered}
M A E=1 / N \sum_{i=1}^{N}\left|M_{(p, s) i}-A_{(p, s) i}\right| \\
M R E=1 / N \sum_{i=1}^{N}\left|M_{(p, s) i}-A_{(p, s) i}\right| / M_{(p, s) i} \times 100 \%
\end{gathered}
$$

where $N$ is the number of samples. Here, $\delta z$ is proportional to $H^{2} / B$ as described in the Eqn 2, which highlights the importance of the positional relation for precision, although few clear reports are available in the literature. Therefore, integrating the value of $L$ into these positional lengths was introduced to indicate the precision, as shown in Eqn 5.

$$
\delta_{Z}=L \times \frac{\delta_{C C D}}{f}
$$

where $L$ is $H^{2} / B$.

Thus, the precision is proportional to the factor of $L$. In fact, a precision comparison under different conditions was performed based on the correlation value of the relationship between $L$ and $M A E$ from the equation $M A E=a \times L$.

In a case where the inner orientation was not accounted for, the value of $a$ was 0.74 , which represents a low precision compared to a $\delta_{z}$ of 0.19 (Fig. 7). However, when the inner orientation was applied, the value of a was 0.057 , indicating a higher precision compared with the $\delta_{z}$ of 0.19 . This is because the $\delta_{z}$ value calculated from Eqn 2 indicates the variation along the z-axis when two points in the rectified pair of images were located one pixel apart in the relative vicinity of matching points. However, in a matching process such as point measurement, these two points were effectively converged into a single pixel. It was found that this photogrammetry system with the inner orientation was 4.5 times as accurate as the results of Rieke and Nearing (2005) at the same distance, L, due to the use of a lower focus length of $19 \mathrm{~mm}$. Based on its performance, the application of this photogrammetry system 
in a research field such as wind and/or water erosion could be helpful in reducing the necessary time and labor. However, the interference effects of rainfall and the physical properties of soil on the system have to be tested in a laboratory before any large field scale application.

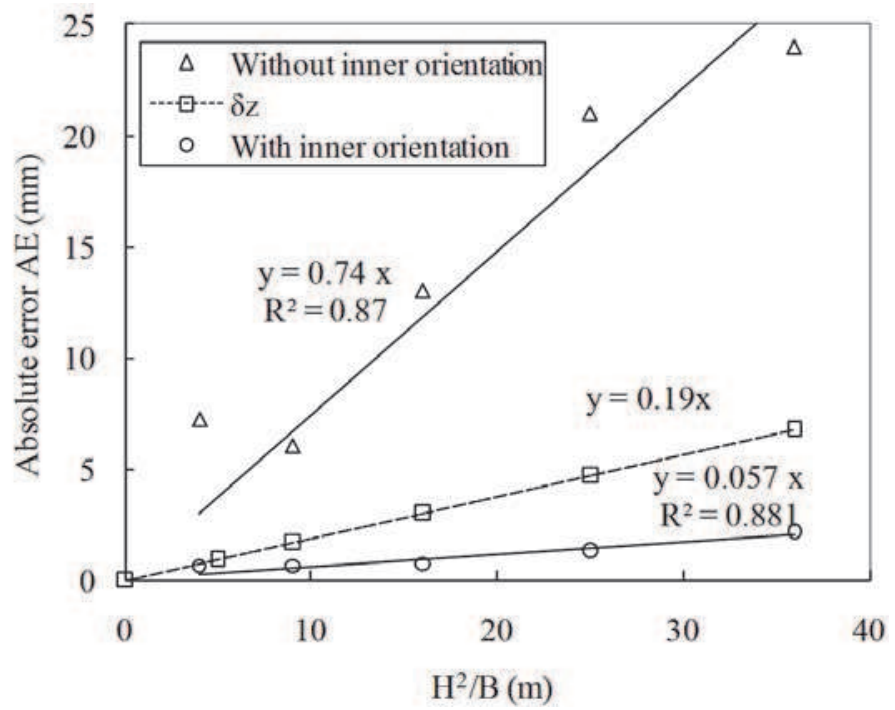

Fig. 7. Relationships between $\mathrm{H}^{2} / \mathrm{B}$ and absolute error $(A E)$. The formulas indicate approximate equation and coefficient of determination.

\subsection{Accuracy of the DEM without the application of rainfall or wind}

The accuracy of the DEM was determined using point and surface measurements with inner orientation. In the point measurement, the value of $a$ was 0.049 , which was a higher precision than the value of 0.057 obtained by the same methods, as previously discussed. This better value was the result of using a closer camera-to-object distance, which produced clearer images. The maximum $H$ was $4.7 \mathrm{~m}$, compared to $7 \mathrm{~m}$ for the above experiment, although the same range was used for $L$ ( 5 to $35 \mathrm{~m}$ ).

In the surface measurement, the value of $a$ was 0.030 , or $63 \%$ higher than for the point measurement; this was because the matching process was conducted automatically based on multi-resolution representations (Kim et al. 1997; Cruz et al. 1995). The DEM value for the cumulative eroded depth was proportional to the measured value. When this proportionality was given as $b$, this value differed from 1.0 according to the increase in $L$, although the coefficient of determination in every case was larger than 0.97 . It was also found that the equilateral was significantly correlated at a $1 \%$ level when the number of samples ranged from 13 to 18 .

\subsection{Accuracy of the DEM under the application of rainfall}

In the field water-capacity procedure, soil samples with three different bulk densities $(0.91$, 0.98 , and $1.09 \mathrm{~g} / \mathrm{cm}^{3}$ ) were subjected to a rainfall intensity of $60 \mathrm{~mm} / \mathrm{h}$. Fig. 8 shows the amount of soil erosion, as determined by the sampling and photogrammetry methods. As 
the soil bulk density increases to $1.09 \mathrm{~g} / \mathrm{cm}^{3}$, the relationship between the sampling and photogrammetry values approaches a slope of 1.0 with a high correlation coefficient. The MAE (MRE) values for densities of $1.09,0.98$, and $0.91 \mathrm{~g} / \mathrm{cm}^{3}$ were $0.59(57.6 \%), 1.07$ $(126.4 \%)$, and $2.21 \mathrm{~mm}(392.5 \%)$, respectively. The accuracy of the DEM was improved considerably when the bulk density increased from 0.91 to $1.09 \mathrm{~g} / \mathrm{cm}^{3}$. This could have been because of the additional compacting of the soil by the rainfall, which likely had less of a compaction effect on the soil surfaces with higher bulk densities. The influence of soil consolidation on the accuracy was also confirmed under different soil conditions, and also with laser scanners under different monitoring capabilities (Scholl et al. 2007; Moritani et al. 2007). The lower accuracy was also confirmed using dry soil subjected to rainfall even under the higher bulk density since the soil was swelled during wetting process, and on the other hand, the soil surface was easily disturbed by drops of rain, especially at the first stage of the experiment as reported in the studies of Moritani et al. (2006). This study shows that the accuracy of DEM under the rainfall could be improved when the additional parameters such as antecedent moisture and hardness condition of the soil surface were investigated.

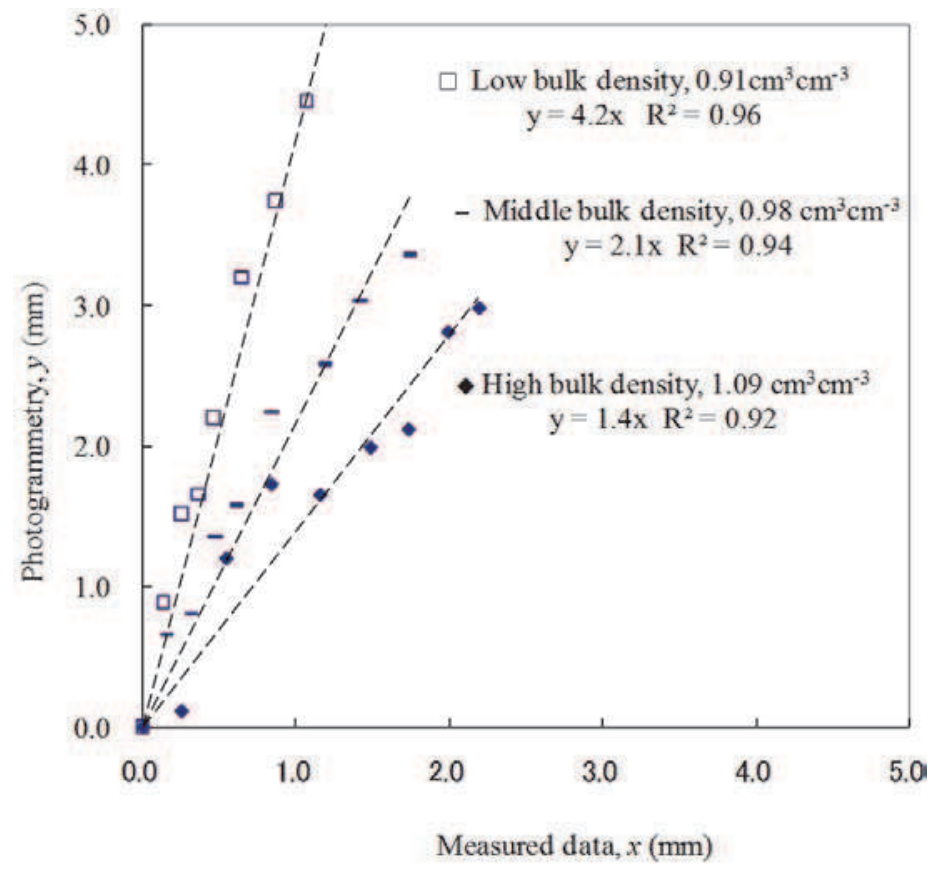

Fig. 8. Relationships between measured and photogrammetry for depth eroded by the rainfall. The formulas indicate approximate equation and coefficient of determination.

$80 \%$ of the soil surface was divided into two regions, upstream and downstream, along the slope. The results show that the quantity of soil eroded in the upstream region was $0.49 \mathrm{~mm}$ greater than in the downstream region (Fig. 9). This observation implies that it is possible to evaluate the amount of soil eroded in a specific area, and monitor the erosion mechanisms. When $L$ was $9.1 \mathrm{~m}$, the characterizing factors for accuracy, $b, M A E$, and $M R E$, were 1.06, 0.21 $\mathrm{mm}$, and $15.8 \%$, respectively. 


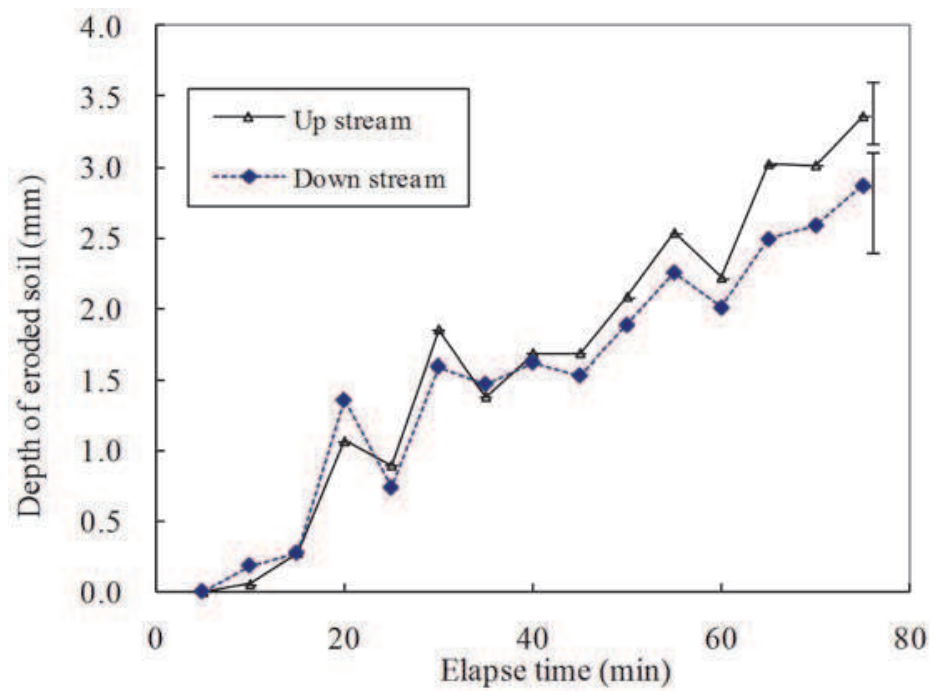

Fig. 9. Depth of eroded soil with elapsed time for up stream and down stream conditions under high bulk density.

Bar is the value of $A E$ at the end of experiment

\subsection{Accuracy of the DEM under the application of wind}

The relationship between wind velocity and the amount of eroded soil is shown in Fig. 10 . The curve in the figure was calculated from Eqn. 6 which has been modified based on the equation of Bagnold (1936).

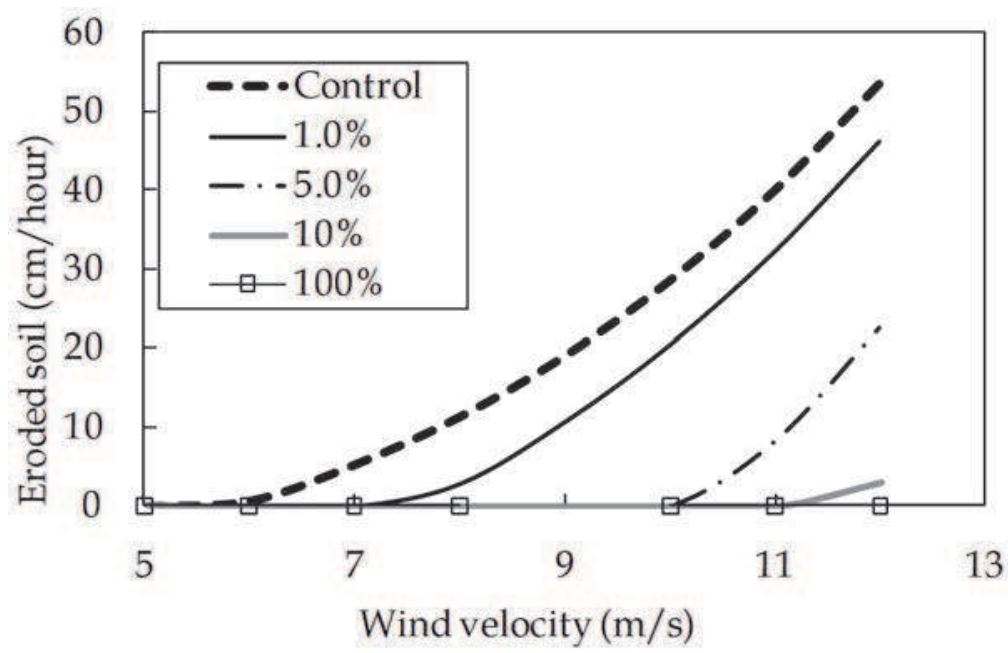

Fig. 10. Relationships between wind velocity and depth of eroded soil The percentage indicate the contents of organic matter 


$$
Q=b\left(u-u_{t}\right)\left(u+u_{t}\right)^{2}
$$

, where $u$ and $u_{t}$ are wind velocity and critical wind velocity at $20 \mathrm{~cm}$ height, respectively. RMSE shows the low value of $0.2-4.1 \mathrm{~cm} /$ hour, which was low error between measured and estimated value. The control soil started to be eroded with $0.01 \mathrm{~mm} /$ hour with low value from $5.0 \mathrm{~m} / \mathrm{s}$ of wind velocity, which was assumed as critical wind velocity. The eroded soil increased sharply from $5.0 \mathrm{~m} / \mathrm{s}$ with increasing wind velocity. Maximum eroded soil of 56.4 $\mathrm{cm} /$ hour was found at the maximum wind velocity of $12 \mathrm{~m} / \mathrm{s}$. The mixture of organic matter reduced the eroded soil. The critical wind velocity in 1.0, 5.0 and $10 \%$ of organic matter were $7.7,8.4$ and $8.9 \mathrm{~cm} /$ hour. The treatment of 1,5 and $10 \%$ mixture with organic matter decreased the eroded soil by $14.2,68.3$ and $92.2 \%$, respectively. This result showed the organic material reduced the wind erosion significantly. The eroded soil in $100 \%$ of organic matter was $0.32 \mathrm{~cm} /$ hour at $12 \mathrm{~m} / \mathrm{s}$ of wind velocity with over than $99 \%$ of reduction than that of control since the cohesion between particles was strongly increased as a result of organic matter application. This result shows that incorporation of the organic material with fiber shape can be use as wind erosion conservation that leads to the sustainable agriculture in the sandy soil.

Fig. 11 shows the shapes of the wind ripples. Here the $M A E$ value for data obtained by the point gauge photogrammetry methods was $0.21 \mathrm{~mm}$. This high precision was obtained because the images were taken before and after the wind events. Monitoring the soil surface under the condition of wind application involves some difficulties such as unclear soil displacement-settlement and dust interference during the photographic process. Therefore, an approach of how to use photogrammetry system method during a wind erosion simulation is needed for further consideration and study. This research focused on the accuracy of photogrammetry when used to measure soil erosion. However, a more specific investigation of soil surfaces in relation to the spatial coherence of erosion/deposition patterns should be performed.

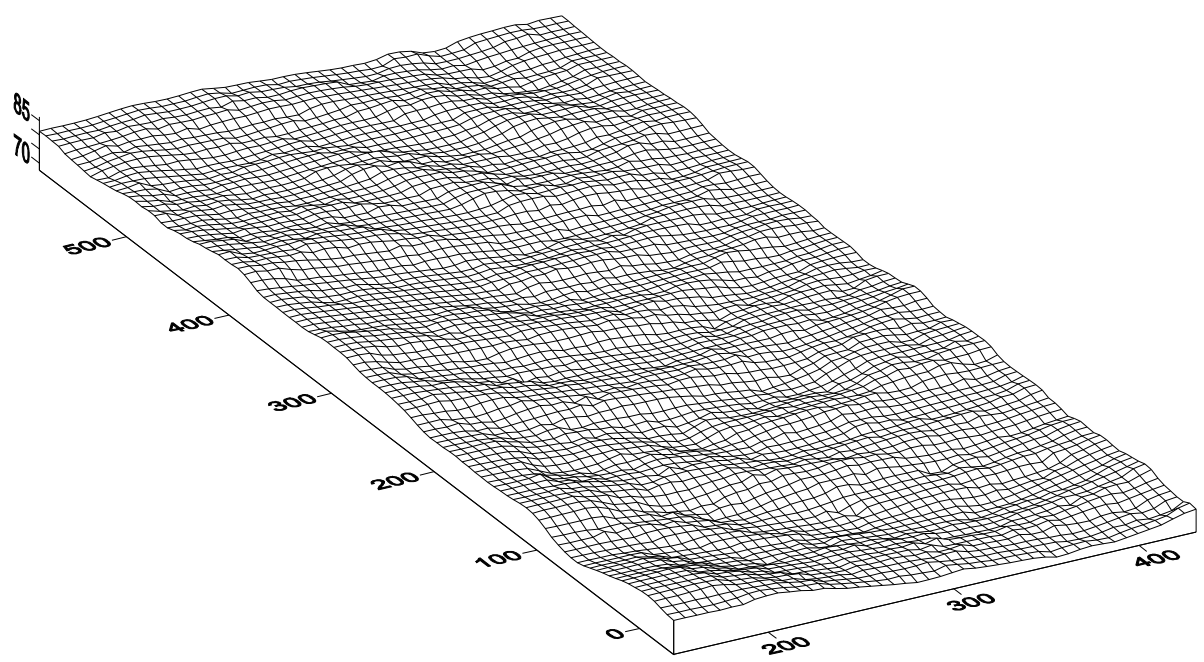

Fig. 11. Grids of the sandy soil surface after wind erosion experiment 


\section{Conclusion}

The experiments of wind and water erosion were performed using wind tunnel and rainfall simulator, respectively. The amount of eroded soil was measured by applying photogrammetry and soil sampling. The amount of soil erosion was estimated by a digital photogrammetry system that used two cameras from difference of soil surface changing. It was found that the accuracy was influenced by declinations in the principal coordinate points of the lenses and the distortion of the lenses. However, these factors could be compensated for by calculating the inner orientation of each camera. The value of the cumulative eroded depth determined by photogrammetry under a no-rainfall or wind condition was significantly proportional to the measured value at the $1 \%$ level, although the accuracy under rainfall was influenced by the soil compaction as a result of the raindrop impact. Therefore, because of its high accuracy, this system could be applied when monitoring the changes in soil surface as result of water and wind erosion, or when measuring the amount of eroded soil in the case of soil with a high bulk density.

The sandy soil is high tolerance against water erosion because of its high permeability. However sandy soil moves easily by wind erosion, which lead to damage for agriculture. It was found that monitoring the sandy soil surface using photogrammetry method under wind application involves some difficulties such as unclear soil displacement-settlement and dust interference. Further study on appropriate use of photogrammetry system method during a wind erosion application is needed to consider. This research focused on the accuracy of photogrammetry when used to measure soil erosion. However, a more specific investigation of soil surfaces in relation to the spatial coherence of erosion/deposition patterns should be performed.

\section{References}

Abd Elbasit MAM, Yasuda H, Anyoji H (2008) Development and application of digital elevation model rectification method in monitoring soil microtopography changes during rainfall. Journal of Japan Society of Hydrology and Water Resources 21 (2), 114-125.

Abd Elbasit MAM, Anyoji H, Yasuda H, Yamamoto S (2009) Potential of low cost closerange photogrammetry system in soil microtopography quantification. Hydrological Processes 23 (10), 1408 - 1417.

Andry H, Yamamoto T, Inoue M (2007) Effectiveness of hydrated lime and artificial zeolite amendments and sedum (Sedum sediforme) plant cover in controlling soil erosion from an acid soil. Australian journal of soil research 45, 266-279.

Andry H, Yamamoto T, Rasiah V, Fukada M (2008) Physico-mechanical processes involved in sediment generation in a simulated acid soil. Transactions of the Japanese Society of Irrigation, Drainage and Rural Engineering 257, 1-9.

Bagnold RA (1936) The movement of desert sand, Proc. R. Soc. London Ser. A 157, pp. 594620.

Brasington J, Smart RMA (2003) Close range digital photogrammetric analysis of experimental drainage basin evolution. Earth Surface Processes and Landforms, 28 (3), 231-247.

Chandler JH, Ashmore P, Paolo C, Gooch M, Varkaris F (2002) Monitoring river-channel change using terrestrial oblique digital imagery and automated digital 
photogrammetry. Annals of the Association of American Geographers 92 (4), 631644.

Chandler JH, Fryer JG, Jack A (2005) Metric capabilities of low-cost digital cameras for close range surface measurement. The Photogrammetric Record 20 (109) 12-26.

Cruz JM, Pajares G, Aranda J, Vindel JLF (1995) Stereo matching technique based on the perceptron criterion function. Pattern Recognition 16 933-944.

Darboux F, Huang C (2003) An instantaneous-profile laser scanner to measure soil surface microtopography. Soil Science Society of America Journal 67 (1), 92-99.

DeRose RC, Gomez B, Marden M, Trustrum NA (1998) Gully erosion in Mangatu Forest, New Zealand, estimated from digital elevation models. Earth Surface Processes and Landforms 23, 1045-1053.

Elliot WJ, Laflen JM, Thomas AW, Kohl KD (1997) Photogrammetric and rillmeter techniques for hydraulic measurement in soil erosion studies. Transactions of the American Society of Agricultural Engineers 40 (1), 157-165.

Heipke C (1997) Automation of interior relative and absolute orientation. ISPRS Journal of Photogrammetry \& Remote Sensing 52, 1-19.

Helming K, Römkens MJM, Prasad SN (1998) Surface roughness related processes of runoff and soil loss. A flume study. Soil Science Society of America Journal 62, 243-250.

Hodge, R., Brasington J, Richards K (2009) In-situ characterization of grain-scale fluvial morphology using Terrestrial Laser Scanning. Earth Surface Processes and Landforms. doi:10.1002/esp.1780

Huang CT, Mitchell OR (1995) Dynamic camera calibration. Institute of Electrical and Electronics Engineers, International Symposium on Computer Vision in 1995, 169174.

Huang C (1998) Quantification of soil surface microtopography and surface roughness. Fractals in Soil Science (Eds. P Baveye, J-Y Parlange, BA Stewart) CRC Press, Boca Raton 432, 153-168.

Huang C, White I, Thwaite EG, Bendeli A (1988) A noncontact laser system for measuring soil surface topography. Soil Science Society of America Journal 52 (2), 350-355.

Jeong S, Cho J, Choi B (2004) An epipolar rectification for object segmentation. Transactions of Institute of Electronics Information and Communication Engineers 87 (5), 14341437.

Jeschke W (1990) Digital close-range photogrammetry for surface measurement. International Archives of Photogrammetry and Remote Sensing 28 (5), 1058-1065.

Kim YS, Lee JJ, Ha YH (1997) Stereo matching algorithm based on modified wavelet decomposition process. Pattern Recognition 30 (6), 929-952.

Lascelles B, Favis-Mortlock D, Parsons T, Boardman J (2002) Automated digital photogrammetry: a valuable tool for small-scale geomorphological research for the non-photogrammetrist. Transactions in GIS 6 (1), 5-15.

Leys JF, Raupach MR (1991) Soil flux measurement using a portable wind erosion tunnel. Australian journal of soil research 29 533-552.

Liu LY, Li XY, Shi PJ, Gao SY, Wang JH, Ta WQ, Song Y, Liu MX, Wang Z, Xiao BL (2007) Wind erodibility of major soils in the farming-pastoral ecotone of China. Journal of Arid Environment 68 611-623.

Lyles L and Tartako J (1986) Wind erosion effect on soil texture and organic matter. Journal of soil water conservation 41 191-193. 
Moritani S, Yamamoto T, Henintsoa A, Muraki H (2006) Monitoring of soil erosion using digital camera under simulated rainfall. Transactions of the Japanese Society of Irrigation, Drainage and Rural Engineering 244, 143-149.

Moritani S, Yamamoto T, Henintsoa A, Muraki H (2007) Monitoring Of Soil Erosion Using Digital Camera Under Simulated Rainfall. American Geophysical Union, Fall Meeting 2007, abstract \#H51E-0826

Pellikka P, Clark B, Hurskainen P, Keskinen A, Lanne M, Masalin K, Nyman-Ghezelbash P, Sirviö T (2004) Land use change monitoring applying geographic information systems in the Taita Hills, Se-Kenya. Proceedings of the 5th AARSE conference (African Association of Remote Sensing of the Environment), 18-21 October, 2004, Nairobi, Kenya.

Prosser IP, Aberneathy B (1996) Predicting the topographic limits to a gully network using a digital terrain model and process thresholds. Water Resources Research 32 (7), 2289-2298.

Pyle CJ, Richards KS (1997) Digital photogrammetric monitoring of river bank erosion. Photogrammetric Record 15 (89), 753-764.

Rieke-Zapp DH, Wegmann H, Santel F, Nearing MA (2001) Digital photogrammetry for measuring soil surface roughness. Proceedings of the American Society of Photogrammetry \& Remote Sensing 2001 Conference, Gateway to the New Millennium, St Louis, Missouri, p8.

Rieke-Zapp DH, Nearing MA (2005) Digital close range photogrammetry measurement of soil erosion. The Photogrammetric Record 20 (109) 69-87.

Römkens MJM, Wang JY, Darden RW (1988) A Laser Microreliefmeter. Transactions of ASAE 31 (2), 408-413.

Scholl BN, Bogonko M, He Y, Beighley RE, Milberg CT (2007) Quantifying the spatial distribution of hill slope erosion using a 3-D laser scanner. American Geophysical Union, Fall Meeting 2007, abstract \#H51E-0826

Shao Y, McTainsh GH, Leys JF Raupach MR (1993) Efficiencies of sediment samples for wind erosion measurement. Australian journal of soil research 31 519-532.

Soil Conservation Service (1976) National range handbook, U.S. Department of Agriculture, Soil Conservation Service, Washington.

Van Dijk AIJM, Bruijnzeel LA, Rosewell CJ (2002) Rainfall intensity-kinetic energy relationships: a critical literature appraisal. Journal of Hydrology 261, 1-23.

Weng J, Cohen P, Herniou M (1992) Camera calibration with distortion models and accuracy evaluation. IEEE Transactions on Pattern Analysis and Machine Intelligence 14 (10) 


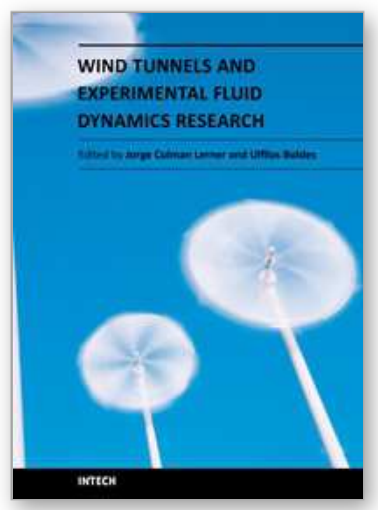

\author{
Wind Tunnels and Experimental Fluid Dynamics Research \\ Edited by Prof. Jorge Colman Lerner
}

ISBN 978-953-307-623-2

Hard cover, 709 pages

Publisher InTech

Published online 27, July, 2011

Published in print edition July, 2011

The book â€œWind Tunnels and Experimental Fluid Dynamics Researchâ€ is comprised of 33 chapters divided in five sections. The first 12 chapters discuss wind tunnel facilities and experiments in incompressible flow, while the next seven chapters deal with building dynamics, flow control and fluid mechanics. Third section of the book is dedicated to chapters discussing aerodynamic field measurements and real full scale analysis (chapters 20-22). Chapters in the last two sections deal with turbulent structure analysis (chapters 23-25) and wind tunnels in compressible flow (chapters 26-33). Contributions from a large number of international experts make this publication a highly valuable resource in wind tunnels and fluid dynamics field of research.

\title{
How to reference
}

In order to correctly reference this scholarly work, feel free to copy and paste the following:

Shigeoki Moritani, Tahei Yamamoto, Henintsoa Andry, Mitsuhiro Inoue, Taku Nishimura, Haruyuki Fujimaki, Reiji Kimura and Hirotaka Saito (2011). Monitoring of Soil Surface under Wind and Water Erosion by Photogrammetry, Wind Tunnels and Experimental Fluid Dynamics Research, Prof. Jorge Colman Lerner (Ed.), ISBN: 978-953-307-623-2, InTech, Available from: http://www.intechopen.com/books/wind-tunnels-andexperimental-fluid-dynamics-research/monitoring-of-soil-surface-under-wind-and-water-erosion-byphotogrammetry

\section{INTECH}

open science | open minds

\author{
InTech Europe \\ University Campus STeP Ri \\ Slavka Krautzeka 83/A \\ 51000 Rijeka, Croatia \\ Phone: +385 (51) 770447 \\ Fax: +385 (51) 686166 \\ www.intechopen.com
}

\author{
InTech China \\ Unit 405, Office Block, Hotel Equatorial Shanghai \\ No.65, Yan An Road (West), Shanghai, 200040, China \\ 中国上海市延安西路65号上海国际贵都大饭店办公楼 405 单元 \\ Phone: +86-21-62489820 \\ Fax: +86-21-62489821
}


(C) 2011 The Author(s). Licensee IntechOpen. This chapter is distributed under the terms of the Creative Commons Attribution-NonCommercialShareAlike-3.0 License, which permits use, distribution and reproduction for non-commercial purposes, provided the original is properly cited and derivative works building on this content are distributed under the same license. 